\title{
Analysis and optimization of bus rollover crashworthiness
}

\author{
Jingyu Liu', ${ }^{1, a}$, Keke Zhang ${ }^{2, b^{*}, \text { Jianning Zhao }}{ }^{3, \mathrm{c}}$ \\ ${ }^{1}$ School of Automobile, Chang'an University, Xi'an, 710064,China. \\ ${ }^{2}$ School of Automobile, Chang'an University, Xi'an, 710064,China. \\ ${ }^{3}$ School of Automotive Studies, Tongji University, Shanghai, 201804,China. \\ a7883617a@163.com, b1078398567@qq.com, c ning328534965@126.com
}

\begin{abstract}
Keywords: Rollover test; closed loop; evaluation method
Abstract. Finite element model of a full load bus is built and a simulation experiment on the rollover crash is carried out. Simulation data is consistent with the experimental data, indicates that the finite element model is effectiveness. Bus superstructure deformation and regularity of energy transfer are analyzed, and find out the weak links of the superstructure. To improve the strength of superstructure according to closed loop principle, and the bus rollover safety performance before and after improvement are evaluated with reference to $\mathrm{PH}$ evaluation method. The results show that bus rollover safety improved obviously, and the design method has reference value to the products development.
\end{abstract}

\section{Introduction}

As we all know, bus is a increasingly important high integral transportation. There are 307 thousand buses and 13.262 million seats at the end of 2014 all over the country, year-on-year growth of $2.6 \%$ and $3.4 \%$ respectively, according to the 2014 statistics bulletin of the transportation industry. At the same time, bus traffic accidents occur repeatedly, and it is easy to cause significant life and property losses especially in the rollover crash accidents. Our country and many bus companies make much account of the performance of a bus rollover crashworthiness. China reference ECE R66/01 regulations and its revision and the contents of errata, issued bus rollover test standard GB 17578-2013 of bus superstructure strength requirements and test methods in 2013, it takes the bus rollover test into the mandatory tests projects, completely replaced the recommended standard GB/T 17578-1998.

Big bus supperstructure should have sufficient strength and rigidity, to ensure the vehicle during or after rollover could have a living space from invasion according to GB 17578-2013. A big bus finite element model of bus rollover is established by HyperWorks in this paper, and analyzed the structural deformation in the process of bus rollover crash by Ls-dyna. The superstructure energy transfer law in the process of collision is studied, the structural deformation in the process of bus rollover is analyzed, and bus body frame rollover collision strength improved effectively after improvement.

\section{Finite element modeling}

Bus general arrangement parameters as shown in table 1, the CATIA components model import into HyperMesh for finite element preprocessing, then assemble into a whole bus model. When the bus body frame simplified in FEM preprocessing, we ignore the process characteristics, and ensure the shape of window pillars, roof longitudinal rails and body understructure beams, and keep connection details between side wall pillars with window cross members, keep details between roof and side wall pillars. Add the top and side surrounding skin and the front windshield glass. Engine, gearbox, clutch, and air conditioning are simplified to rigid body of the same quality and center of mass. All passengers and seats are equivalent weight processed at the center of mass, tires and suspension are added in finite element modeling. At last, we ensure that the deviation of mass center height between finite element model and the real bus within $20 \mathrm{~mm}$.

This paper adopt $20 \mathrm{~mm} \times 20 \mathrm{~mm}$ rectangular grid as a benchmark to mesh the bus, there are 687726 elements in all, and the number of triangle elements are 5916 and account for less than $1 \%$, the bus 
completely finite element model as shown in figure 1. This paper adopt BT shell element to simulate the algorithm of frame structure proposed by Belytschko and Tsay, and apply Johnson-Cook model simulate the material of body parts. Set the time step parameter is 0.9 , and ascertain the step of time is $9.68 \mathrm{e}-7 \mathrm{~s}$ by regulating the elements' density, and the element quality increased less than $1 \%$. Symmetric penalty function method is used to control the ratio of hourglass relative to internal energy within 5\%, reduce the situation of elements have a case of deformation without strain energy. Set point-surface contact between bus and rollover platform, both static and dynamic friction coefficient are 0.4; set automatic single surface contact between the bus parts itself, both static and dynamic friction coefficient are 0.2; set surface-surface contact between bus and rigid ground, static and dynamic friction coefficient of each set as 0.6 and 0.4 .

In the experimental process, any moving parts should not invade the living space, and should not appear the situation of structure completely broken, and any parts in the living space should not be extruded outside of the deformation structure. The simulation model living space is usually set as rigid body, and its position in the bus as shown in figure 2 .

Table 1. General arrangement parameters

\begin{tabular}{lccc}
\hline Parameter & Value & \multicolumn{1}{c}{ Parameter } & Value \\
\hline $\begin{array}{l}\text { Total Length } \\
/[\mathrm{mm}]\end{array}$ & 11990 & F/R tread $/[\mathrm{mm}]$ & $2070 / 1860$ \\
$\begin{array}{l}\text { Total width } \\
/[\mathrm{mm}]\end{array}$ & 2550 & $\begin{array}{l}\text { F/R slacklength } \\
/[\mathrm{mm}]\end{array}$ & $2540 / 3300$ \\
$\begin{array}{l}\text { Total height } \\
/[\mathrm{mm}]\end{array}$ & 3600 & $\begin{array}{l}\text { Approach } / \text { Departure } \\
\text { angle } /\left[^{\circ}\right]\end{array}$ & $9 / 9$ \\
$\begin{array}{l}\text { Wheelbase } \\
/[\mathrm{mm}]\end{array}$ & 6150 & F/R axle load $/[\mathrm{kg}]$ & $6500 / 11500$ \\
Total mass $/[\mathrm{kg}]$ & 18000 & Unladen mass $/[\mathrm{kg}]$ & 12700 \\
\hline
\end{tabular}

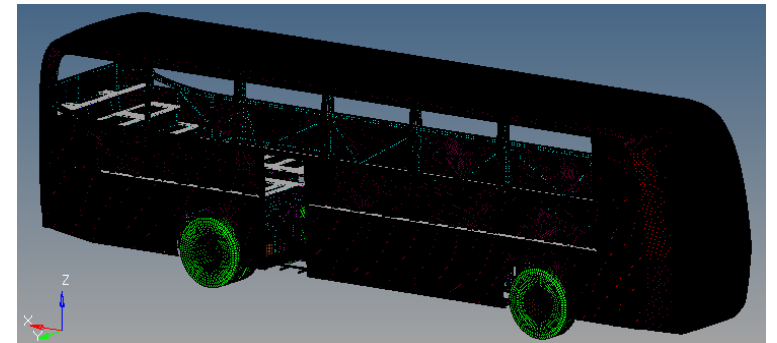

Fig. 1 Bus finite element model

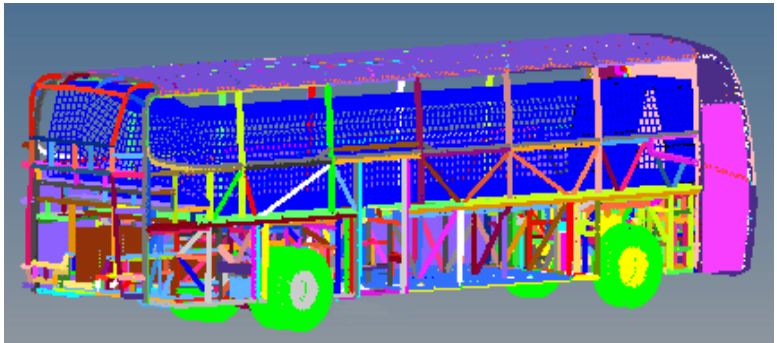

Fig.2 Living space

\section{Rollover simulation analysis and superstructure improvement}

\subsection{Rollover simulation analysis}

Rollover simulation and real bus test are in accordance with bus superstructure strength requirements and test methods and also refer to ECE/R66 in this paper. Bus finite element model is placed on the turning platform, and set the initial angular velocity as $1.875 \mathrm{rad} / \mathrm{s}$, then the rotate platform steady lifting the bus, until it reaches a critical location and the platform stop turning, the relatively more dangerous side of living space is the crash direction, and simulation time set as 400ms on the basis of real bus rollover crash time. Rollover model is imported into the explicit nonlinear finite element solver Ls-dyna to calculate.

Simulation combine with real bus experiment, is an important way to verify the effectiveness of the finite element model and is an important way of products development. Real bus rollover test has been tested before simulation, and test data is measured with deformation rules. As we can see from table 2, the relative deviation between $3.3 \%$ and $10.4 \%$ of simulation and real bus experiment date, illustrate that the effectiveness of the finite element model. In addition, because of the simplified finite element modeling, the real bus experiment value is less than the simulation value always of a 
same pillar, and that is to say, if the bus rollover simulation meets requirements and the real bus tests will meet the requirements too.

Table 2. Contrast of simulation and real bus test data

\begin{tabular}{lllllll}
\hline $\begin{array}{l}\text { Distance } \\
\text { between } \\
\begin{array}{l}\text { nodes } \\
\text { and floor }\end{array}\end{array}$ & $\begin{array}{l}\text { Pillar1 } \\
\text { Simulat }\end{array}$ & $\begin{array}{l}\text { Pillar1 } \\
\text { Experi } \\
\text { mental }\end{array}$ & $\begin{array}{l}\text { Pillar 2 } \\
\text { Simulati } \\
\text { on }\end{array}$ & $\begin{array}{l}\text { Pillar 2 } \\
\text { Experim } \\
\text { ental }\end{array}$ & $\begin{array}{l}\text { Pillar 3 } \\
\text { Simulati } \\
\text { on }\end{array}$ & $\begin{array}{l}\text { Pillar 3 } \\
\text { Experim } \\
\text { ental }\end{array}$ \\
\hline $500[\mathrm{~mm}]$ & 78 & 75 & 75 & 70 & 127 & 115 \\
\hline $700[\mathrm{~mm}]$ & 126 & 120 & 120 & 115 & 135 & 126 \\
\hline $1250[\mathrm{~mm}]$ & 132 & 140 & 283 & 270 & 295 & 285 \\
\hline
\end{tabular}

Energy change in the process of bus rollover crash as shown in figure 3. It can be seen that total energy increase at begin due to the gravity, and bus kinetic energy convert into internal energy at the begin of bus touches the ground. Because of the structure deformation has a small amount of rebound, internal energy is slightly decreased after $175 \mathrm{~ms}$. The maximum hourglass energy is $3.91 \mathrm{e} 6 \mathrm{~J}$ at $400 \mathrm{~ms}$ and is $4.39 \%$ of the total energy. The energy absorption of superstructure accounting for $92 \%$ of the whole bus energy absorption, and is greater than the regulations of $75 \%$. In addition, the energy ratio as shown in figure 4 , its range within $1 \pm 0.05$ and that is reasonable. And the skin accounts for the total energy absorption ratio is $5.86 \%$, showing that skin has a great influence on the performance of bus rollover. To sum up, bus rollover crash finite element model energy conservation meets requirements, and the deviation meets the demand of engineering, so the simulation analysis is stable and effective.

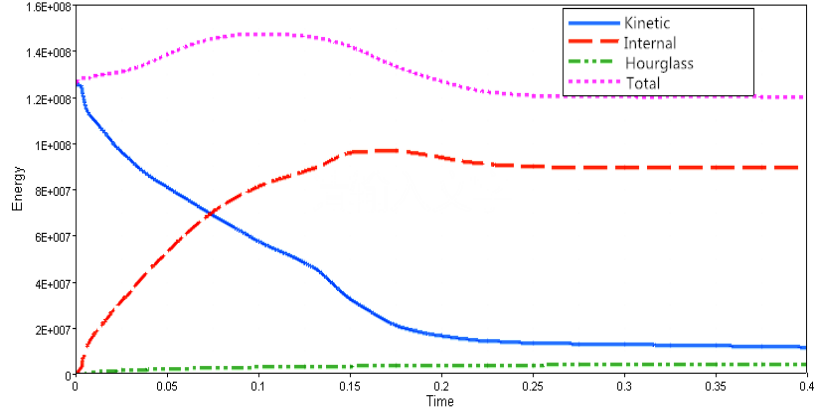

Fig. 3 Bus energy curves

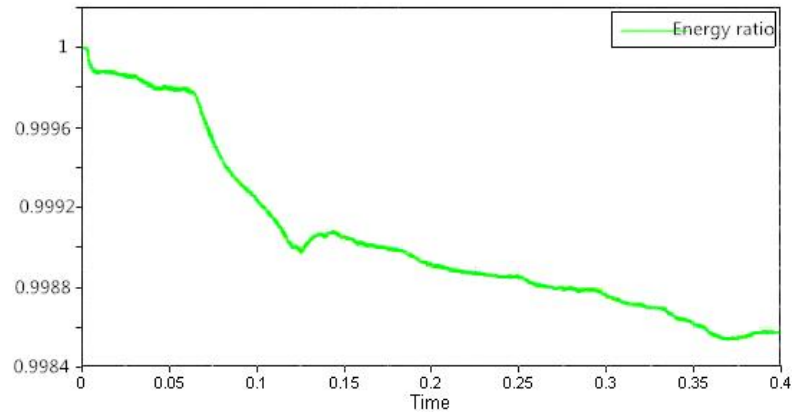

Fig. 4 Energy ratio curve

Bus rollover simulation result as shown in figure 5. During the bus rollover crash, the roof rail first touchdown, cause the stress of the longitudinal rail material beyond the yield limit and appears plastic deformation, then the force of collision flowing to the left side of the roof rails, the roof panel and side window pillars; Skin has obviously deformation at 30ms; Right side pillars and front wall have obviously deformation at $125 \mathrm{~ms}$; the left penultimate side pillar has the maximum deformation at $144 \mathrm{~ms}$ of the whole bus; then the deformation begin to rebound until the end of the simulation, the distance between pillars and living space increase to $8.07 \mathrm{~mm}$.

By observing the simulation results, we find that the body frame exists some deficiencies in the process of bus rollover crash. Such as, the structure of under window beams and window pillars and roof members are weak, so the crash force quickly flow to the side window pillars, and the force can't pass through the roof members to the right side of the bus in time, and that lead the bus body frame deformation is big and its order inappropriate. Because of engine and transmission locate at the back of the bus, the deformation of rear body is seriously. At the left side wall penultimate pillar appears maximum deformation of the whole bus, and the distance between side wall pillars and living space is only $1.84 \mathrm{~mm}$. The experimental results meet requirements, but the living space may be invaded at a big possibility, bus body frame structure remains to be further improved. 


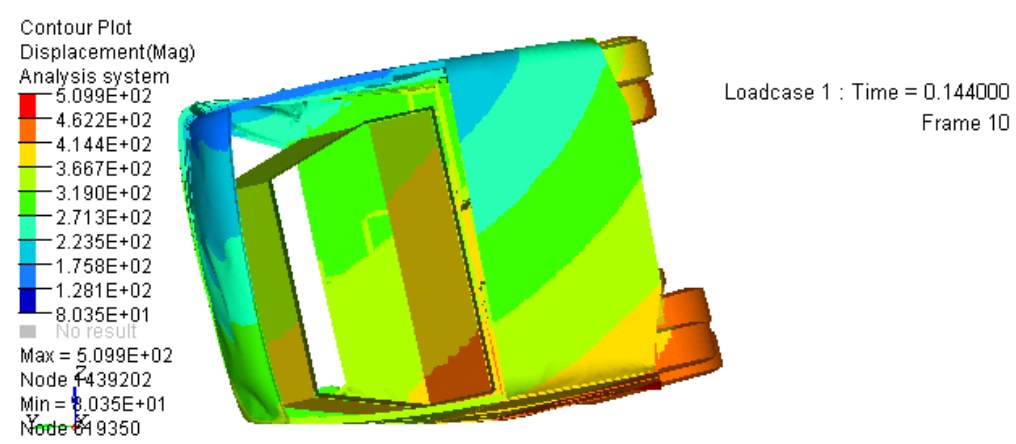

Fig. 5 Bus rollover crash simulation result

\subsection{Superstructure improvement}

By the observation of the bus model and comparison of several optimization schemes, this paper decides adopt the principles of closed loop structure and side wall is the important energy absorption structure, to improve the bus rollover crash performance, and ensure the body frame structure protect passengers living space effectively. This paper improve the original bus body frame structure in accordance with the following schemes.

The "big ring" refers to the roof members, side window pillars, floor members and baggage compartment beams constitute a closed loop; "small ring" means baggage compartment beams don't alignment with the other beams. Therefore, this paper aligned baggage compartment beams with side wall pillars and aligned floor members with side wall pillars, make sure that the body structure meets the "big ring" closure principle. As we know, the collision force pass through roof members and side wall pillars firstly when rollover crash, the type of through type pillars, body understructure cross members and baggage compartment beams constitute a closed loop, so the collision force could directly flow to understructure cross members or baggage compartment beams. So the side wall skeleton adopt through type pillars instead of through type window under beams, make sure that the side wall pillars are the important energy absorption structure. We moved 4 beams of the body frame as shown in figure 6, and it caused some body understructure beams, rear end frame beams and side wall pillars have a small amount of modified, and the mass of the bus hardly any change at all.

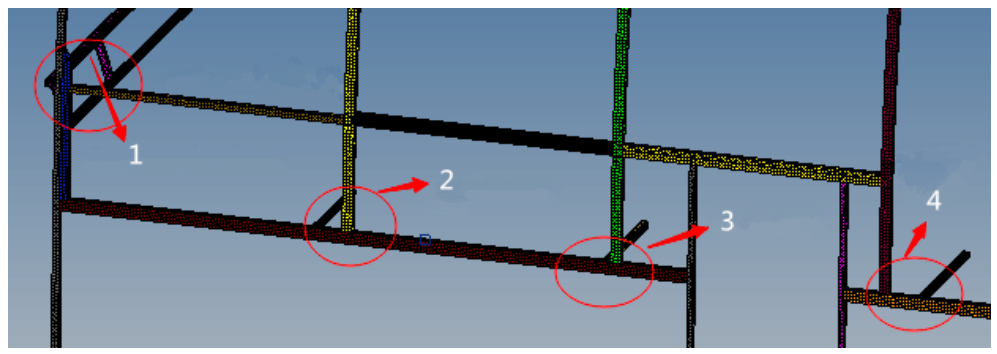

Fig. 6 Structure improvement figure

\section{PH evaluation method of the superstructure strength}

There are no quantitative assessment indicator of rollover crash safety of bus body frame structure in the standards all over the world. This paper adopt $\mathrm{PH}$ evaluation method to evaluate a certain type big bus rollover safety performance, and we use $\mathrm{PH}$ evaluation method evaluate the deformation of the penultimate pillar only, make sure that the strength of the superstructure is enough.

Deformation index of bus superstructure is $\mathrm{DI}_{\alpha}=\mathrm{f}\left(\Delta \alpha_{1}, \Delta \alpha_{2}\right)$, and its principle diagram as shown in figure 7. When we do not consider the influence of bend beam transition zone angle, the index can be expressed as equation (1).

$$
\mathrm{DI}_{\alpha}=\frac{\mathrm{l}}{400} \tan \left(\Delta \alpha_{1}\right)+\frac{1250-1}{400} \tan \left(\Delta \alpha_{2}\right)
$$

When $\mathrm{DI}_{\alpha}<0.4$, superstructure strength is very high and $\mathrm{PH}$ evaluation is 5 stars; When $0.4 \leq \mathrm{DI}_{\alpha}<0.8$, superstructure strength is relatively high and $\mathrm{PH}$ evaluation is 4 stars; When $0.8 \leq \mathrm{DI}_{\alpha}<1$, superstructure strength is general and $\mathrm{PH}$ evaluation is 3 stars; When $1 \leq \mathrm{DI}_{\alpha}<1.2$, superstructure 
strength is poor and $\mathrm{PH}$ evaluation is 2 stars; When $1.2 \leq \mathrm{DI}_{\alpha}$, superstructure strength is unacceptable and $\mathrm{PH}$ evaluation is 1 star.
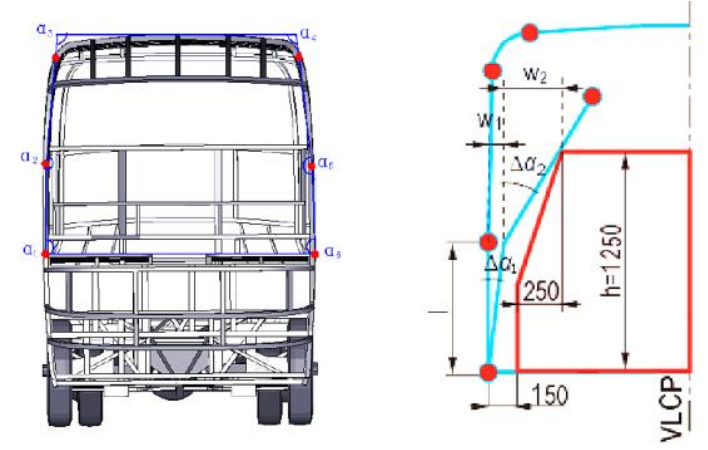

Fig. 7 PH evaluation method

The original structure simulation analysis is carried out, angle curves of $\alpha_{1}$ and $\alpha_{2}$ as shown in figure 8 , we can calculate that $\Delta \alpha_{1}=13.96^{\circ}, \Delta \alpha_{2}=9.84^{\circ}$, and for the known bus model parameter $1=$ $735 \mathrm{~mm}$, so we can get that $\mathrm{DI}_{\alpha}=0.428$, and superstructure $\mathrm{PH}$ evaluation is 4 stars. The improved bus model is calculated by Ls-dyna also, and the largest safety margin is $12.3 \mathrm{~mm}, 10.5 \mathrm{~mm}$ bigger than the original structure. The $\alpha_{1}$ and $\alpha_{2}$ change curves of the side wall pillar maximum deformation after improved as shown in figure 9. We can get that $\Delta \alpha_{1}=13.075^{\circ}, \Delta \alpha_{2}=-1.31^{\circ}, \mathrm{DI}_{\alpha}=0.397$, so the superstructure PH evaluation is 5 stars, and the big bus body superstructure strength is very high.

Bus body frame static strength and modal are calculated before and after improvement, in the two kinds working conditions of full load bending and twisting, the maximum stress were $109.7 \mathrm{Mpa}$ and $131.6 \mathrm{Mpa}$ of each other, and the strength of the bus body frame structure increased slightly than before. The whole bus first order torsional frequency is $8.5 \mathrm{~Hz}$, and it remains the same with before. In conclusion, the strength of bus superstructure enhanced and bus rollover safety performance is very good after optimization, and the structure improvement principle is effectiveness.

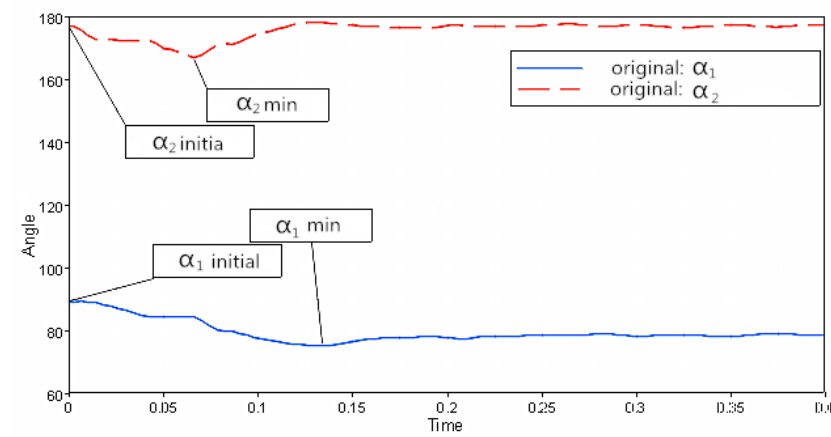

Fig. 8 Original structure angle curves of $\alpha_{1}, \alpha_{2}$

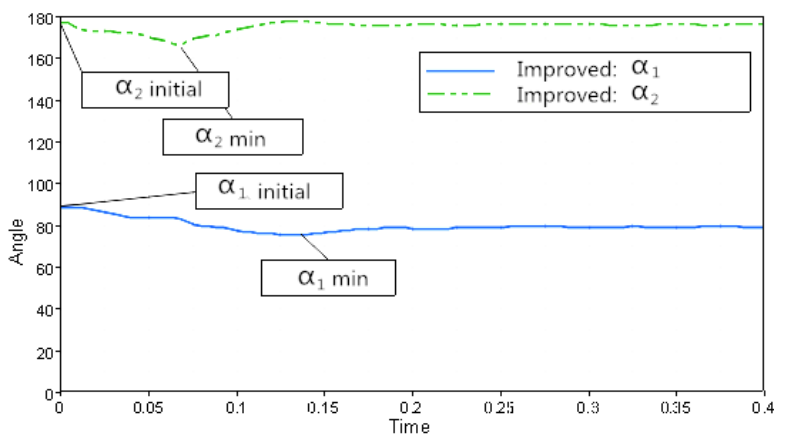

Fig. 9 Improved structure angle curves of $\alpha_{1}, \alpha_{2}$

\section{Summary}

Simulation data compared with experimental data proves that the finite element model is correctly. The combination of simulation and real bus test is the important way to validate and improve the bus rollover crashworthiness performance.

Bus body frame energy transfer regularity and superstructure deformation are analyzed, and improve bus body frame structure in accordance with the principle of closed loop. Adopt PH evaluation method evaluate the bus rollover safety performance before and after optimization, the superstructure rollover crashworthiness level improved from 4 stars to 5 stars. The type of side wall pillars have great influences on energy transfer in the process of bus rollover crash, closed loop structure and through type pillars can reduce big bus side wall crushing deformation effectively. 


\section{References}

[1] GB 17578-2013, Bus superstructure strength requirements and test methods [S]. China Standards Press, 2013

[2] ECE/R66/01,Uniform Technical Prescriptions Concerning the Approval of Large Passenger Vehicles with Regard to the Strength of Their Superstructure [S].

[3] Wenguo Qi. Simulation and optimization of bus rollover crash safety performance based on the ECE/R66 regulations [J]. Automotive Engineering Journal, 2010, 12 (32nd roll)

[4] Junliang Jiu. Rollover crash performance and passengers injury research of commuter bus [D]. Chang 'an university, 2011

[5] Hailei Chang. Bus body frame static strength analysis and rollover test simulation [D]. Chang 'an university, 2013

[6] Ruifeng Yang. A bus superstructure strength based on the strength of the superstructure of ECE/R66 regulations [J]. Journal of highway traffic science and technology, 2011.10

[7] Bojanowski C., Wekezer J., Kwasniewski L., Kownacki J. Florida Standard For Crashworthiness And Safety Evaluation Of Paratransit Buses[J]. ENHANCED SAFETY OF VEHICLES,2009

[8] Guanfei Cha. Rollover test simulation and security research of big bus body structure [D]. Chongqing university, 2011 